\title{
A New Agent-Based Model Provides Insight Into Assumptions in Modeling Forest Management Under Deep Uncertainty
}

Garry Sotnik ( $\sim$ gsotnik@gmail.com )

University of Michigan https://orcid.org/0000-0002-2422-1110

Brooke A. Cassell

Portland State University

Matthew J. Duveneck

Harvard University

Robert M. Scheller

North Carolina State University

\section{Research Article}

Keywords: agent-based model, comparative analysis, deep uncertainty, forest management

Posted Date: February 15th, 2021

DOl: https://doi.org/10.21203/rs.3.rs-192142/v1

License: (c) (i) This work is licensed under a Creative Commons Attribution 4.0 International License.

Read Full License

Version of Record: A version of this preprint was published at Landscape Ecology on August 21st, 2021.

See the published version at https://doi.org/10.1007/s10980-021-01324-5. 


\section{Abstract}

Context

Exploratory modeling in forestry uses a variety of approaches to study forest management questions. One key assumption that every approach makes is about the degree of deep uncertainty-the lack of knowledge required for making an informed decision-that future forest managers will face. This assumption can strongly influence simulation results and the conclusions drawn from them, but is rarely studied.

Objectives

Our objective was to measure the degree of deep uncertainty within a forest management simulation to compare alternative modeling approaches and improve understanding of when a specific approach should be applied.

Methods

We first developed a method for measuring the degree of deep uncertainty assumed by approaches to modeling forest management. Next, we developed a new extension to the LANDIS-II model, the SOSIEL Harvest Extension, which simulates alternative approaches to modeling forest management. Finally, we applied the new method and extension to comparing three alternative approaches to modeling forest management in Michigan.

Results

The degrees of deep uncertainty varied substantially among the three modeling approaches. There is also an overall negative relationship between the degree of deep uncertainty an approach assumes a forest manager will face and the level of flexibility the approach assumes a manager will have in responding to forest change.

Conclusions

Quantifying the deep uncertainty inherent in simulated forest management and comparing it across models provides an opportunity to better understand its sources and investigate differences in the assumptions made by alternative modeling approaches.

\section{Introduction}

Forests provide ecosystem services that are essential for human well-being (Brockerhoff et al., 2017; MEA, 2003), which makes their sustainable management a global priority (e.g., European Commission, 2003; Robertson et al., 2011). However, forest management is complex and presents both ecological and economic challenges, especially under climate change and other exogenous factors. The complexity 
underlying forest dynamics and the unpredictability of human (e.g., development, market shocks, policy) and natural (e.g., wildfires, insect infestations) disturbances limit the information that is available for long-term forest management decisions, such as how, how much, and when to best harvest trees (Amacher, 2015; Messier et al., 2016; Puettmann et al., 2009). Climate change further complicates decision making by changing the phenology, growing-season length and timing, optimal geographic ranges of forest tree species, and disturbance regimes in unforeseen ways (Handler et al., 2014; Rosenzweig et al., 2007; Swanston et al., 2018; Turner \& Romme, 1994). For example, management choices must consider the climate and forest structural conditions required for present-day tree establishment, while increasingly taking into account that the trees will need to mature under future and potentially unanticipated conditions (Park et al., 2014). Such complexities create an environment of deep uncertainty (Lempert et al., 2003, 2006; Marchau et al., 2019; Walker et al., 2013), which is characterized by insufficient information about a problem at hand, its external drivers, and the potential outcomes. This form of uncertainty is different from other forms, which can be reduced through further study or accounted for using statistics (Walker et al., 2013), and it poses a great challenge for forest management and planning.

Such a deep level of uncertainty reduces the value of many forecasting models that rely on assigning specific probabilities to or on ranking potential futures (Kwakkel et al., 2010; Lempert et al., 1996; Walker et al., 2003, 2013). As an alternative, researchers and planners often opt for exploratory models that instead test plans across a broad range of potential futures, with the aim of identifying the plan that produces the most acceptable results across the largest number of futures (Bankes, 1993; Lempert, 2019; Lempert et al., 1996; Lucash et al., 2017; Maier et al., 2016; Weaver et al., 2013). The futures and plans in such exploratory models are often dynamic, which further reflects the deep uncertainty of any specific future scenario and of how a decision-maker may attempt to make adjustments over time (Lempert, 2019; Lempert et al., 1996; Walker et al., 2001; Weaver et al., 2013). Such exploratory models have the potential to capture at least three sources of deep uncertainty that decision-makers face: not knowing (a) which future is more likely to occur; (b) how a specific future may evolve, possibly in response to the influence of a specific plan; and (c) how well decision-makers within any one of the potential futures will be able to make adjustments as that future evolves.

Exploratory modeling is frequently applied in forestry to study forest management questions, with approaches to modeling forest management varying widely. For example, some models do not include dynamic forest management (Albert et al., 2015, 2018; Handler et al., 2014; Keeley et al., 2009; Maxwell et al., 2020; Seidl \& Lexer, 2013), some include dynamic but probabilistic forest management (e.g., Mayer \& Rouleau, 2013; Rouleau \& Zupko, 2019; Wear et al., 2013; Zupko \& Rouleau, 2019), and others include dynamic feedback-based forest management (e.g., Barros et al., 2017; Rammer \& Seidl, 2015) and at multiple scales (e.g., Bolte et al., 2007). Such differences, which implicitly reflect assumptions about the degree of deep uncertainty future forest management will face, substantially contribute to simulation outcomes (Rinaldi \& Jonsson, 2020) but are rarely discussed in this context (but see Yousefpour et al. [2012], who review the differences in non-exploratory approaches to modeling forest management under uncertainty). Although general limitations in the ability to model human behavior (Elsawah et al., 2020; 
Meyfroidt, 2013; Sotnik, 2020) and to measure deep uncertainty (Chow \& Sarin, 2002; Gomory, 1995) prevent identifying any specific approach as the most accurate, finding ways to measure and compare approaches would clarify their differences and stimulate a much-needed discussion about when a specific approach should be applied.

In this paper, we first propose a method for measuring the degree of deep uncertainty assumed by an approach to modeling forest management. We then describe a new SOSIEL Harvest Extension (SHE) for LANDIS-II (Scheller et al., 2007), which simulates alternative approaches to modeling forest management, and apply SHE to compare three approaches to modeling management of forested U.S. Forest Service (USFS) land in Michigan. We simulated the three approaches with the same forest succession model (Duveneck et al., 2014) in order to isolate the modeling approach as the variable determining deep uncertainty faced by future management. After presenting the results, we compare the assumed degree of deep uncertainty across the three approaches and discuss their applicability under alternative forest conditions.

\section{Methods And Data}

We first describe our novel method for quantifying deep uncertainty within models of forest management. We then describe SHE, a new extension to the LANDIS-II model that we introduce in this study. This is followed by a brief description of the data from Duveneck et al. (2014), which we used to parameterize the LANDIS-II extensions: Biomass Succession (Scheller \& Mladenoff, 2004), Base Wind (Mladenoff \& He, 1999), Biomass Harvest (BHE) (Gustafson et al., 2000), which, in this study, SHE calls to implement forest management, and SHE.

\subsection{A new method for measuring the degree of deep uncertainty assumed by a modeling approach}

Multiple methods using empirical data and model output to estimate deep uncertainty already exist (Shaw, 2017a; Uusitalo et al., 2015). Perhaps the most common method is the use of the standard deviation of a quantity of interest (e.g., Baker et al., 2016; Bloom, 2009; Shaw, 2017c). However, an increase in the variability of a quantity does not necessarily translate into an increase in its deep uncertainty (if a trend is still present). On the other hand, the predictability of the quantity may be a useful marker of uncertainty (Jurado et al., 2015). Therefore, we use the extent to which a simulated forest manager is unable to achieve a goal through its actions as an indicator of the degree of deep uncertainty assumed by the approach to modeling the manager. Our method relies on the reasonable assumption that the simulated forest manger is at least implicitly a boundedly-rational decision-maker (Gigerenzer \& Selten, 2001; Selten, 1998; Simon, 1957, 1960; Todd et al., 2012), i.e., they attempt to make the best decisions possible under existing limitations in cognition and information, which hinder timely acquisition of required knowledge. This premise implies that any significant inability of the simulated forest manager to reasonably set and achieve a goal is due to a substantial lack of required knowledge, i.e., deep uncertainty. 
We applied a simple linear regression model to estimate the relationship between the result of simulated management, which in our case is represented by the annual amount of biomass harvested (Tg) through simulated timber harvests, and the management goal, which is to maintain the percentage of mature forest in the management area at or above its initial age. The resulting simple linear regression model takes the following form:

MaturityPercent $_{t}=\mathrm{a}+\beta^{\star}$ HarvestAmount $_{t-1}+\varepsilon_{\mathrm{t}}$

HarvestAmount $_{t-1}$ (the predictor variable) in $\mathrm{Tg}$ is what the simulated forest manager has direct and complete control over (as long as the quantity of biomass to be harvested is less than the amount available for harvesting). MaturityPercent $t_{t}$ (the predicted variable) is what the simulated forest manager only has indirect and incomplete control over via HarvestAmount $t_{t-7}$. The MaturityPercent ${ }_{t}$ variable accounts for the differences in user-defined species' sexual maturity ages and is first calculated for each cohort and then aggregated for each site and stand to produce the percentage for the entire management area.

The simple linear regression model was selected (instead of a more complex model that may have provided a better fit between the two variables) in part for its generality and the ease with which it may be applied in different contexts but also because our aim was to propose a method that assessed boundedly-rational decision-making across a wide range of approaches, rather than identifying the best fitting model for a specific context. We then used the model's adjusted coefficient of determination (Devore, 2012), $r^{2} \in[0,1]$, to estimate the degree of deep uncertainty an exploratory approach to modeling forest management assumes forest management will face. Specifically, we used: $1-r^{2}$, which represents the proportion of the variance in the predicted variable (MaturityPercent $t_{t}$ ) that was unexplainable by the predictor variable (HarvestAmount $t_{t-1}$ ), to estimate the degree of deep uncertainty assumed by an approach. As a result, the estimated degree of deep uncertainty is unit neutral and, therefore, comparable among agents within one multi-agent model, among different approaches to modeling or altogether different models, and even among different contexts. The statistical analysis was conducted in $\mathrm{R}$ (version 4.0.2; R Core Team, 2020).

The Akaike Information Criterion (Akaike, 1974; Burnham et al., 2011; Burnham \& Anderson, 2002b; Halsey, 2019) and the Bayesian Information Criterion (Burnham \& Anderson, 2002a, 2004; Schwarz, 1978), which are used for comparing the goodness of a model's fit, were also considered as candidates for representing the assumed degree of deep uncertainty. The statistics were not selected in part because they assume that the predicted variable in all of the compared regression models is the same, which is not true in our case because we are comparing different regression models, in their entirety, and not just different combinations of predictor variables in a single regression model with the same predicted variable; and in part because they are not normalized, which makes it unclear how to measure their reverse-the lack of good fit. 


\subsection{A new agent-based model for simulating boundedly- rational forest use and management}

LANDIS-II (version 7; Scheller et al., 2007) is a dynamic forest model that employs extensions to simulate forest succession and management under a variety of disturbances, such as fire (e.g., Cassell et al., 2019; Krofcheck et al., 2019), insects (e.g., Scheller et al., 2018), and wind (e.g., Lucash et al., 2019). LANDIS-II uses tree species life-history traits, as well as soil and climate data, to simulate succession and responses to disturbance over time within modeled landscapes. Trees are modeled as species-age cohorts, where a cohort represents individual trees of a species and age group. Forested vegetation, topographical, and climate conditions are assumed to be homogeneous within landscape sites, within which competition, growth, and mortality are simulated. Disturbances and seed dispersal are simulated both within and among sites.

In this study, we use LANDIS-II's Biomass Succession (version 5.2; Scheller \& Mladenoff, 2004) extension to simulate establishment, growth, and competition of trees, the Base Wind (version 3.1; Mladenoff \& He, 1999) extension to simulate wind events and to induce wind-caused tree mortality, and a new agentbased forest management extension, SOSIEL Harvest (version 1.1), to simulate boundedly-rational forest management. The Biomass Succession extension uses species-specific parameters, such as shade tolerance and seed-dispersal distances, to simulate aboveground changes in forest biomass based on tree-cohort establishment, growth, and mortality (Scheller \& Mladenoff, 2004). The Base Wind extension simulates wind events that cause tree-cohort mortality. Wind event frequency and size are based on wind rotation period, and cohort mortality is determined by user-defined susceptibility of tree age-cohorts (by percent maturity of individual species) to increasing wind intensity (Mladenoff \& He, 1999).

The new SOSIEL Harvest extension (SHE) couples LANDIS-II and its Biomass Harvest extension (BHE) (version 4.3; Gustafson et al., 2000) to the agent-based SOSIEL (Self-Organizing Social \& Inductive Evolutionary Learning) algorithm (version 2.4; Sotnik, 2018), which simulates boundedly-rational decision-making by one or more agents. This coupling of extensions gives SHE access to BHE's rich library of forest management design and implementation options, as well as input files for parametrizing prescriptions that are already familiar to many LANDIS-II users.

Together, LANDIS-II with SHE has the potential to simulate adaptive management in coevolving coupled human and forest landscapes (Fig. 1), which occurs when there is feedback between two or more evolving systems (Durham, 1991; Janzen, 1980; Nuismer, 2017). As a forest simulated by LANDIS-II evolves, it is shaped by internal dynamics as well as climate conditions, forest management, and other disturbances (e.g., fire, insects, windthrow). Forest management, in turn, is shaped by forest conditions and, potentially, by other personal and social dynamics. This interaction drives structural change in both the forest and its management. Management changes the forest structurally through the addition (planting) and removal (harvesting) of trees. Management itself also changes structurally in response to forest conditions through the addition (innovation) and removal (forgetting) of decision options. Such changes across generations and harvesting seasons produces coevolutionary dynamics. 
Each SOSIEL agent makes decisions using a cognitive architecture (Goertzel et al., 2010; Kotseruba \& Tsotsos, 2018; Langley, 2017; Langley et al., 2009) that consists of nine cognitive processes (anticipatory learning, goal prioritizing, counterfactual thinking, innovating, social learning, goal selecting, satisficing, signaling, and action-taking) that enable each agent to interact with other agents, learn from its own experience and that of others, and make decisions about taking, and then take, (potentially collective) actions. Specifically, anticipatory learning uses change in the states of an agent's goals to update the anticipated influences of its decision options and its confidence in its ability to attain the corresponding goals. Goal prioritizing applies what an agent learned during anticipatory learning to reevaluate the relative importance of its goals and, if necessary, reprioritize them. In the case an agent loses confidence in its ability to achieve a specific goal, counterfactual thinking checks whether the agent would have behaved differently, i.e., would have chosen an alternative decision option, had it known what it just learned during anticipatory learning. If the agent would have behaved differently, i.e., if it would have chosen an alternative decision option that was readily available, then confidence is regained and the agent moves on to social learning. If the agent would not have behaved differently, i.e., if it does not have a useful decision option for the current situation, then confidence remains lost and the agent moves on to innovating. Innovating uses the information learned by an agent during anticipatory learning and the prior period's decision to create a new decision option. Social learning informs an agent of the actions taken in the prior period by its social network neighbors by adding the actions to the agent's corresponding mental models. Goal selecting orders an agent's goals by their updated relative importance levels and chooses one for each situation the agent is set to take action in. Satisficing uses the updated anticipated influences of decision options to select, for each situation, a decision that best meets an agent's goal within that situation. In the case the selected decision option is a collective action, the agent signals its interest in engaging. If a sufficient number of others are also interested in engaging in the collective action, they all commit to engaging. Otherwise, they reactivate the process of satisficing to once again choose a decision option that best meets their specific goals. The final process is action-taking, which implements the selected decisions.

A SOSIEL agent can respond to its external and internal conditions by switching between its decision options, which are conditional (IF/THEN) statements. These statements are parameterizable with forest, personal, and/or social antecedents (the IFs) and a forest consequent (the THEN). The SOSIEL algorithm organizes decision options into mental models, which are an agent's mental representation of a situation and each of which is associated with one or more goals, such as managing a specific species. Decision options in any two mental models are complementary, in that they do not compete with each other's implementation, whereas decision options within a single mental model are substitutes, with only one selected for implementation during the SOSIEL process of satisficing. This design permits agents to take part in a diverse set of situations, with access to a diverse and specific-to-them set of decision options, and in pursuit of a diverse and specific-to-them set of goals. In addition to switching between decision options, an agent can also respond by reprioritizing the relative importance of its goals. If an agent's confidence in its ability to achieve a goal with its current set of decision options is lost, it is further capable of using its experience to create new decision options. 
Additionally, the SOSIEL algorithm provides the option to regulate the cognitive level of agents in a specific simulation. The cognitive levels bundle the aforementioned cognitive processes in a way that corresponds to existing approaches to modeling agent cognition (Sotnik, 2018). Currently, agents can engage in boundedly-rational decision-making at the following four cognitive levels:

- Cognitive level 1: An agent chooses a decision option from among those available to it (within a specific mental model) based on the influence it anticipates the decision option will have on a goal. The SOSIEL cognitive processes activated at this level are: goal selecting, satisficing, signaling, and action-taking.

- Cognitive level 2: An agent additionally (to what it is capable of in cognitive level 1) uses feedback from the forest to update the influence it anticipates an implemented decision option will have on a goal, to update its level of confidence in its ability to achieve the goal, and, if necessary, to reprioritize its goals. The additional SOSIEL cognitive processes activated at this level are: anticipatory learning and goal prioritizing.

- Cognitive level 3: Agents can additionally (to what they are capable of in cognitive level 2) learn from each other. The additional SOSIEL cognitive process activated at this level is: social learning.

- Cognitive level 4: An agent can additionally (to what it is capable of in cognitive level 3) reconsider its prior period's actions and, if dissatisfied with its ability to achieve its goal(s), create new decision options. The additional SOSIEL cognitive processes activated at this level are: counterfactual thinking and innovating.

SHE operates in two modes: on its own (Mode 1), which is primarily intended for simulating site-scale forest management, and integrated with BHE (Mode 2), which is intended for simulating stand-tolandscape-scale forest management (Fig. 2). In Mode 1, SHE calls the SOSIEL algorithm to analyze forest conditions and choose decision options and then uses LANDIS-II's harvest management libraries (Gustafson et al., 2000) to implement them. In Mode 1, a many-to-many relationship is possible between agents and forest management areas, which they can share. Additionally, decisions are made and implemented at the forest-site level, which permits the implementation of decision options at the neighborhood scale $(0-50 \mathrm{~m})$. Such decision options are typically implemented by community forest members (e.g., Agrawal \& Angelsen, 2009; Gilmour, 2016; Ostrom, 1999), family forest landowners (e.g., Fischer, 2019; Gan et al., 2015; Winter \& Fried, 2000), wildlife management and wildlife (e.g., Carter et al., 2012; Shepherd \& Whittington, 2006), and may also be useful as part of forest management efforts aimed at biodiversity and overall management at multiple spatiotemporal scales (e.g., Puettmann et al., 2009). Agents can move through a landscape from one forest site to another and choose which of its decision options to implement, based on forest, personal, or social conditions (or combinations of all three).

We used Mode 2 in this study. In Mode 2, SHE first calls the SOSIEL algorithm to analyze forest conditions and choose decision options, and then SHE calls BHE to implement the decision options related to forest management. In Mode 2, each decision option in the SOSIEL algorithm pairs with a 
corresponding prescription in BHE (Fig. 3). The name of a decision option and the decision option's consequent (the THEN) serve as the link between it and the corresponding prescription. For SHE, each BHE prescription consists of two components: one that describes what to manage and how (parameterized through BHE's prescriptions table) and another that specifies the percentage of the management area in which the prescription is to be implemented (parameterized through BHE's implementation table). In the current version of SHE, the value of a decision option's consequent corresponds to the percentage of the management area to which the paired prescription is to be applied. If only one forest manager agent is simulated, there is a one-to-many relationship between the agent and forest management areas. If multiple agents are being simulated, there is a one-to-one relationship between the agents and management areas.

The SOSIEL algorithm can create new decision options in both Modes 1 and 2 (Fig. 4). The process involves using a user-adjustable probability distribution to increase/decrease the consequent value of an existing decision option in the direction that the agent perceives would improve its ability to achieve its most highly prioritized goal. As a result, the only difference between the prior decision option and the new decision option is the value of its consequent. In Mode 2, SHE additionally creates a new BHE prescription where the new decision option's consequent value defines the percentage of the management area in which the prescription is to be implemented. SHE also adjusts all of the new prescription's biomass removal percentages in the same direction and to the same extent it adjusted the percentage of the management area. As a result, a new prescription differs from the one prior both in the percentage of the management area in which the prescription is to be implemented and the percentage of the biomass to remove.

\subsection{Three exploratory approaches to modeling forest management}

We used SHE in Mode 2 to simulate three exploratory approaches to modeling forest management under deep uncertainty. Mode 2 is well suited to our forest management dataset from Duveneck et al. (2014), which is landscape-scale and implemented at the stand level. We used the SOSIEL algorithm's cognitive levels 1,2 , and 4, respectively (Table 1 ) to simulate the three approaches, A1 (predefined), A2 (expanded), and A3 (innovation). We skipped cognitive level 3 because in this study we simulated the forest management of only one forest manager at a time, thereby precluding the possibility for social learning. To account for stochasticity in forest dynamics and wind disturbance, we simulated three replicates of each approach. Results were first calculated for each of the three replicates of each of the three approaches (nine replicates in total) and then averaged across each replicate set to derive one set of results for each approach. 
Table 1

The three modeling approaches $(A 1-3)$ compared in this study, descriptions of their corresponding cognitive levels (CL1V3), and comparable approaches in the field.

\begin{tabular}{|c|c|c|c|}
\hline Approach & $\begin{array}{l}\text { Cognitive } \\
\text { level }\end{array}$ & Description & $\begin{array}{l}\text { Comparable } \\
\text { approaches }\end{array}$ \\
\hline \multirow[t]{3}{*}{$\mathrm{A} 1$} & \multirow[t]{3}{*}{ CL1 } & \multirow{3}{*}{$\begin{array}{l}\text { What and how much the agent harvests are predetermined } \\
\text { before simulation start by a set of predefined decision } \\
\text { options. Current forest conditions influence how the stands } \\
\text { are ranked, which stands qualify for harvest, which forest } \\
\text { sites are selected, and which cohorts are removed. The use } \\
\text { of percentages in determining how much of a specific } \\
\text { cohort is to be removed further aligns harvest intensity with } \\
\text { current forest conditions. }\end{array}$} & $\begin{array}{l}\text { Albert et al. } \\
(2015)\end{array}$ \\
\hline & & & $\begin{array}{l}\text { Albert et al. } \\
(2018)\end{array}$ \\
\hline & & & $\begin{array}{l}\text { Gustafson } \\
\text { et al. (2000) }\end{array}$ \\
\hline \multirow[t]{4}{*}{ A2 } & \multirow[t]{4}{*}{ CL2 } & \multirow{4}{*}{$\begin{array}{l}\text { What and how much the agent harvests are determined by } \\
\text { an expanded (compared with A1/CL } 1 \text { ) set of predefined } \\
\text { decision options, the agent's ability to use its experience to } \\
\text { update the anticipated influence of implemented decision } \\
\text { options, and its ability to choose the best decision options } \\
\text { accordingly. Note: Goal reprioritizing does not activate in our } \\
\text { study because the forest manager has only one goal. }\end{array}$} & $\begin{array}{l}\text { Barros et al. } \\
\text { (2017) }\end{array}$ \\
\hline & & & $\begin{array}{l}\text { Mayer \& } \\
\text { Rouleau } \\
(2013)\end{array}$ \\
\hline & & & $\begin{array}{l}\text { Rammer \& } \\
\text { Seidl (2015) }\end{array}$ \\
\hline & & & $\begin{array}{l}\text { Wear et al. } \\
(2013)\end{array}$ \\
\hline A3 & CL4 & $\begin{array}{l}\text { What and how much the agent harvests are additionally } \\
\text { (compared with } A 2 / C L 2 \text { ) determined by its ability to create } \\
\text { new decision options when the existing decision options are } \\
\text { not sufficient in helping it achieve its goal. }\end{array}$ & $\begin{array}{l}\text { Bolte et al. } \\
(2007)\end{array}$ \\
\hline
\end{tabular}

One important difference between A1 (predefined), on the one hand, and A2 (expanded) and A3 (innovation) on the other, is how the goal of maintaining the percentage of mature forest in the management area at or above its initial value is incorporated. In A1, we incorporated the goal implicitly into the design of the prescriptions. The goal was not specified in Duveneck et al. (2014) but we assumed it here because the prescriptions represent a business-as-usual strategy. In contrast, we explicitly incorporated the goal and its relationship with each decision option (see Sec. 2.4) in A2 and A3. In designing the three approaches, we developed an overview, design concepts, and details (ODD) protocol (Grimm et al., 2006, 2010, 2020; Müller et al., 2013) that describes the differences among the three approaches in greater detail (see Supplemental Material).

\subsection{Forest management parameterization in Michigan}

We parameterized LANDIS-II, BHE, and Base Wind with the simulation parameters described in Duveneck et al. (2014) (Table 2). Forest succession (tree establishment, growth, competition, age-related mortality), disturbance (wind events and wind-induced mortality), and forest management (harvesting, planting), were implemented at 5-year timesteps with corresponding data output at 5-year intervals. The tools available to the simulated forest managers in A1 (predefined) and A3 (innovation) included 33 decision options in the form of harvest prescriptions (defined in Duveneck et al., 2014) that varied in their target 
species and age groups, the type of harvest (e.g., more intensive clear cuts, less intensive selective harvesting), the percentage of management area to manage and biomass to remove, and whether to plant new species-age cohorts. The simulated forest manager in A3 (innovation) had the additional option of expanding the above number of decision options by creating new ones when it was dissatisfied with its ability to achieve its goal. The manager in A3 can create one decision option per mental model, which translates into no more than 33 per timestep. To imitate forgetfulness and make A3 comparable to A2 (see below), we limited the number of decision options a mental model can contain at any point in time to three, i.e., 99 in total.

Table 2

Select configuration details of each approach (A1-A3), including the initial or total number of decision options (DOs), the limit on the number of decision options in a mental model (MM), how the goal (maintain percentage of mature trees equal to or above $70 \%$ ) is modeled, the relationship between decision options and goals, the corresponding cognitive level (CL), and the cognitive processes activated during simulation.

\begin{tabular}{|c|c|c|c|}
\hline Select configuration details & A1 & A2 & A3 \\
\hline \# of DOs & $\begin{array}{l}33 \\
\text { (total) }\end{array}$ & 99 (total) & 33 (initially) \\
\hline Max \# of DOs/MM & NA & NA & 3 \\
\hline Goal modeled & Implicitly & Explicitly & Explicitly \\
\hline Relationship between DOs and goal & NA & NA & Negative \\
\hline Cognitive level & CL1 & CL2 & CL4 \\
\hline \multirow[t]{5}{*}{$\begin{array}{l}\text { Cognitive processes activated during simulation. Note: } \\
\text { Goal prioritizing is not activated in A2 and A3 because } \\
\text { the managers have only one goal. }\end{array}$} & NA & $\begin{array}{l}\text { Anticipatory } \\
\text { learning }\end{array}$ & $\begin{array}{l}\text { - Anticipatory } \\
\text { learning }\end{array}$ \\
\hline & & $\begin{array}{l}\text { - Goal } \\
\text { selecting }\end{array}$ & $\begin{array}{l}\text { Counterfactual } \\
\text { thinking }\end{array}$ \\
\hline & & - Satisficing & •Innovating \\
\hline & & & $\begin{array}{l}\text { - Goal } \\
\text { selecting }\end{array}$ \\
\hline & & & - Satisficing \\
\hline
\end{tabular}

For the forest manager in A2 (expanded), we parameterized BHE with 66 additional prescriptions to allow for dynamic decision-making. Specifically, we created two new prescriptions from each of the 33 original prescriptions in Duveneck et al. (2014) and added them to BHE's prescriptions and implementation tables, resulting in 33 combinations of three or 99 prescriptions in total. In addition to the original prescription, each combination contained one prescription in which the values for percentages of management area to manage and biomass removed were increased by $10 \%$ from the original and one in which these values were decreased by $10 \%$. 
For A2 and A3 (innovation), we additionally parameterized SHE and SOSIEL in line with the SOSIEL algorithm's configuration requirements (Sotnik, 2018) and BHE's initial dataset. We introduced a goal: to maintain the percentage of mature trees (MaturityPercent $t_{t}$ ) in the forest manager's management area equal to or above $70 \%$ (the approximate percentage at the start of simulation). For the forest manager in $A 3$, we set the relationship between each of the decision options (prescriptions) and the goal to negative. This is because increasing the percentage of mature trees requires reducing the percentage of the management area that is harvested. We also used the standard (power law) form of SOSIEL's general probability distribution for generation of the consequent values for new decision options. The power law distribution was created by assigning the probability of 0.01 to the least likely event, and then calculating each more likely event by multiplying 0.01 by 1.475 . The result was a power law distribution that consisted of the following ten segments: $0.33,0.22,0.15,0.10,0.06,0.05,0.03,0.02,0.02$, and 0.01 .

In summary, the modeled forest manager in A1 had access to the original 33 decision options, the forest manager in A2 to 99 decision options (33 original plus $66 \mathrm{new}$ ), and the forest manager in A3 to the original 33 plus the ability to create new decision options (with a limit of 99 at any point in time). SHE's input files for each approach are available at the following GitHub page: https://github.com/LANDIS-IIFoundation/Project-Michigan-Compare-Harvesting-2021.

\section{Results}

During year 5 , the percentage of mature biomass declined in all simulations from the initial $70 \%$ to 59 $60 \%$ (Table 3). Starting with year 10, harvest actions differed among the three approaches. The forest manager in $\mathrm{A} 1$ (predefined) continued implementing the original 33 decision options for the remainder of the simulation, which resulted in varying harvested amounts from year to year because of changes in available biomass (Table 3 ).

The forest manager in A2 (expanded) first used the feedback (during year 10) from the forest to update the anticipated influences of the original decision options implemented in year 5 and then assessed the percentage of mature biomass as unsatisfactory. The manager then compared the updated anticipated influences of the implemented decision options with those of other decision options and, for each mental model, chose a different set of decision options to implement, namely those with $10 \%$ lower area harvested and $10 \%$ lower harvest amount. Because the forest manager had only one goal, and because the percentage of mature biomass never reached $70 \%$, the manager continued implementing these decision options (i.e., those with the lowest available harvest area and amount) for the remainder of the three simulations.

The forest manager in A3 (innovation) also responded to this unfavorable feedback (during year 10) by updating the anticipated influences of the implemented decision options and also assessed the percentage of mature biomass as unsatisfactory. The manager then chose to create 33 additional decision options that harvested less than their corresponding original decision options, increasing its total number of decision options to 66 . In two of the simulation replicates, this process of assessment 
and, when necessary, creation of new decision options continued on and off until the goal was reached in year 100, at which point the simulated manager stopped harvesting. In one of the replicates, the goal was never reached, and the process continued until the end of the simulation. The manager created new decision options only when those implemented in the prior period moved it away from achieving its goal and when it could not find any decision options in its corresponding mental models that it perceived as having the potential of doing better. Because the manager had only one goal, to maintain mature tree cohorts above $70 \%$, it stopped harvesting when the goal was met, waiting until harvesting was once again necessary to achieve this goal. As a result, the agent created, on average, 319 decision options during a simulation, with the total number of decision options at any point in time never passing 99 . 
Table 3

Select results and statistics from the simulations of the three approaches, including percent mature tree cohorts, amount of biomass harvested, the number of decision options used, and calculated deep uncertainty expressed as $1-r^{2}$. Values are averages across the three replicates for each approach, with the corresponding standard deviations in parentheses.

\begin{tabular}{|c|c|c|c|}
\hline Result & A1 & A2 & A3 \\
\hline \multicolumn{4}{|c|}{ Percent mature (\%) } \\
\hline Initial & 70 & 70 & 70 \\
\hline Year 5 & $59(0.00)$ & $60(0.04)$ & $60(0.07)$ \\
\hline Min & $53(0.00)$ & $54(0.09)$ & $53(0.11)$ \\
\hline Average & $59(0.02)$ & $61(0.05)$ & $66(4.02)$ \\
\hline Max & $64(0.71)$ & $65(0.26)$ & 78 (9.98) \\
\hline Year 150 & $58(0.00)$ & $61(0.26)$ & $78(10.40$ \\
\hline \multicolumn{4}{|c|}{ Harvested (Tg) } \\
\hline Year 5 & $4.0(0.01)$ & $3.5(0.01)$ & $3.5(0.00)$ \\
\hline Average & $6.5(0.01)$ & $5.9(0.02)$ & $3.5(1.62)$ \\
\hline Year 150 & $8.3(0.16)$ & $7.6(0.07)$ & $1.0(1.78)$ \\
\hline Total & $189.6(0.17)$ & $171.7(0.46)$ & $100.0(47.06)$ \\
\hline \multicolumn{4}{|l|}{ \# of DOs } \\
\hline Start & 33 & 99 & 33 \\
\hline End & 33 & 99 & 99 \\
\hline \multicolumn{4}{|c|}{ Regression statistics } \\
\hline $1-r^{2}$ & $0.76(0.01)$ & $0.56(0.03)$ & $0.39(0.36)$ \\
\hline$p$-value & $0.008(0.00)$ & $0.000(0.00)$ & $0.006(0.01)$ \\
\hline
\end{tabular}

Results illustrate differences among the three approaches in their assumed deep uncertainty and ability to approach the goal of at least $70 \%$ mature tree cohorts. The assumed degrees of deep uncertainty (1 $r^{2}$ ) were $0.76,0.56$, and 0.39 for A1 (predefined), A2 (expanded), and A3 (innovation), respectively, with corresponding $p$-values all below our threshold of 0.05 (Table 3). Figure 5 illustrates the corresponding differences in the scatterplots of the three approaches and, in the case of $A 3$, replicates. The scatterplots illustrate a positive relationship between the percent mature and amount harvested variables in $\mathrm{A} 1$ and $\mathrm{A} 2$, and both a negative and a positive relationship in A3. 


\section{Discussion}

Quantifying the deep uncertainty inherent in simulated forest management and comparing it across models provides an opportunity to better understand its sources and investigate differences in the assumptions made by alternative modeling approaches. A major factor contributing to the deep uncertainty faced by all of the simulated forest managers was the small percentages of management area harvested. At any one timestep, the 33 original decision options were preset to harvest 0.01 to $3.7 \%$ of the forest, with $14.21 \%$ harvested in total. Such low percentages challenged management of a rapidly growing forest and amplified the deep uncertainty stemming from forest dynamics.

Another major factor that influenced the degree of deep uncertainty confronted by all of the forest managers was the original design of the decision options. The quantity harvested by any one of the decision options was a percentage of available biomass. In A1 (predefined), this translated into the managers' actions being entirely reactive and proportionally fixed to forest dynamics. In A2 (expanded), the managers initially proactively adjusted their behavior in pursuit of their goal, but then, in the same way as the managers in $A 1$, reacted in fixed proportion to the forest dynamics for the remainder of their simulations. This explains the positive correlation between the percentage of mature tree cohorts and biomass harvested in all but two (A3-R1 and A3-R3) of the simulation replicates (Fig. 5). An increase in biomass led to an increase in the percentage of mature trees, which then led to an increase in the quantity harvested, and vice versa. Only the forest managers in A3-R1 and A3-R3 (innovation) were able to proactively use new, substantially different decision options to offset this underlying positive relationship and gain control over their own behavior in what were, ultimately, successful attempts to influence the percentage of mature tree cohorts on the landscape.

Comparison of $1-r^{2}$ for the three modeling approaches indicates an overall negative relationship between the degree of deep uncertainty an approach assumes a forest manager will face and the level of flexibility the approach assumes a manager will have in responding to forest change. It is intuitive that when behavioral assumptions are frontloaded and not updated during a simulation through feedback, as in A1 (predefined), there will likely be more deep uncertainty in management throughout a simulation as the forest changes over time. Furthermore, as the differences among the scatterplots of the A3 simulation replicates illustrate (Fig. 5), accounting for innovation in future forest management introduces additional uncertainty in simulation results, which stems from the inability to predict exactly how a simulated forest manager will adjust during a simulation. Specifically, the second simulation replicate of A3 (R2) produced behavior much more similar to that in A1 than that in A3's other two replicates (R1 and R3), which we see as an example of conservative innovation.

The ability to influence forest dynamics and capture additional uncertainty in simulation results suggest that $A 3$ (innovation) is preferable to $A 1$ (predefined) and $A 2$ (expanded), and $A 2$ to $A 1$, in the context of the land in Michigan. However, A3 might not be preferable under many other relevant forest conditions. The forest and disturbance dynamics in this study's simulated landscape were relatively predictable and stable over time. A less predictable forest could produce fewer clear trends in predictor and response 
variable relationships. Under such forest conditions, it might be more realistic to assume that a real-world forest manager would apply a less flexible approach, closer to A2 or A1. This highlights the importance of appropriately matching modeling approaches to forest conditions. We need to apply the method across a wider range of forest conditions to more fully assess its usefulness and draw conclusions.

Our method for measuring the degree of deep uncertainty assumed by a modeling approach does not need to be limited to its simple form and is applicable beyond analyzing assumptions. Expanding the number of predictor variables may be useful in cases where forest management pursues its goal through more than one variable. In such cases, the degree of deep uncertainty would be measured by $1-R^{2}$ (Devore, 2012). The number of predicted variables (goals) could also be expanded, in which case multivariate multiple regression (Izenman, 2008) could be used. Additionally, the measurements of the degree of deep uncertainty may be used for purposes other than analyzing assumed degrees of deep uncertainty. For example, it may also be used as part of the criteria for reducing model selection bias by basing estimates on combinations of models (Burnham et al., 2011; Hansen \& Sargent, 2015; Rinaldi \& Jonsson, 2020). Using the measurements of deep uncertainty to select models in such efforts could ensure that the models are sufficiently diverse in their assumptions about the degree of deep uncertainty they entail.

This study demonstrates the ability of SHE, in concert with LANDIS-II, to simulate three substantially different approaches to modeling forest management as well as illustrates the usefulness of our linear regression modeling method in comparing assumed deep uncertainty among modeling approaches. It is also worth noting that there are other SOSIEL cognitive processes in SHE that have the potential to influence the degree of deep uncertainty faced by simulated forest managers. Specifically, SHE is capable of modeling the pursuit of multiple goals, as well as using an agent's degree of success in achieving a specific goal to adjust the goal's relative importance through the SOSIEL cognitive process of goal prioritizing. These functions have the potential of reflecting more of the deep uncertainty faced by realworld forest managers, especially when the goals are conflicting (e.g., profit vs. biodiversity). SHE is also capable of simulating more than one agent at a time, which permits social learning and collective action among them. These functions introduce processes that real-world forest managers use to overcome uncertainty (e.g., management of common-pool resources; Ostrom, 1999). Activating these functions in SHE to study their influence on the degree of deep uncertainty faced by simulated forest managers has the potential to further improve forest management modeling efforts.

\section{Declarations}

Funding: Not applicable

Conflicts of interest/Competing interests: Not applicable

Ethics approval: Not applicable

Consent to participate: Not applicable 
Consent for publication: Not applicable

Availability of data and material: LANDIS-II's and its extensions' input files may be downloaded from the following website: https://github.com/LANDIS-II-Foundation/Project-Michigan-Compare-Harvesting-2021

Code availability: LANDIS-II and its extensions may be downloaded from the following website: http://www.landis-ii.org/. Code for each of the extensions is open source and available on LANDIS-II's GitHub page: https://github.com/LANDIS-II-Foundation

Authors' contributions: Not applicable

\section{Acknowledgements:}

We are grateful to EffectiveSoft Corp. for programming support.

\section{References}

Agrawal, A., \& Angelsen, A. (2009). Using community forest management to achieve REDD+ goals. In A. Angelsen, M. Brockhaus, M. Kanninen, E. Sills, W. D. Sunderlin, \& S. Wertz-Kanounnikoff (Eds.), Realising REDD+: National strategy and policy options (pp. 201-212). Center for International Forestry Research.

Akaike, H. (1974). A new look at the statistical model identification. IEEE Transactions on Automatic Control, 19(6), 716-723. https://doi.org/10.1109/TAC.1974.1100705

Albert, M., Hansen, J., Nagel, J., Schmidt, M., \& Spellmann, H. (2015). Assessing risks and uncertainties in forest dynamics under different management scenarios and climate change. Forest Ecosystems, 2(1), 14. https://doi.org/10.1186/s40663-015-0036-5

Albert, M., Nagel, R.-V., Sutmöller, J., \& Schmidt, M. (2018). Quantifying the effect of persistent dryer climates on forest productivity and implications for forest planning: A case study in northern Germany. Forest Ecosystems, 5(1), 33. https://doi.org/10.1186/s40663-018-0152-0

Amacher, G. S. (2015). The forest harvesting problem: Have we reached the limit of our understanding? In R. Halvorsen \& D. F. Layton (Eds.), Handbook on the Economics of Natural Resources (pp. 206-248). Edward Elgar Publishing Limited.

Baker, S. R., Bloom, N., \& Davis, S. J. (2016). Measuring Economic Policy Uncertainty. The Quarterly Journal of Economics, 131(4), 1593-1636. https://doi.org/10.1093/qje/qjw024

Bankes, S. (1993). Exploratory Modeling for Policy Analysis. Operations Research, 41(3), 435-449. https://doi.org/10.1287/opre.41.3.435

Barros, A. M. G., Ager, A. A., Day, M. A., Preisler, H. K., Spies, T. A., White, E., Pabst, R. J., Olsen, K. A., Platt, E., Bailey, J. D., \& Bolte, J. P. (2017). Spatiotemporal dynamics of simulated wildfire, forest management, 
and forest succession in central Oregon, USA. Ecology and Society, 22(1), art24.

https://doi.org/10.5751/ES-08917-220124

Bloom, N. (2009). The Impact of Uncertainty Shocks. Econometrica, 77(3), 623-685.

https://doi.org/10.3982/ECTA6248

Bolte, J. P., Hulse, D. W., Gregory, S. V., \& Smith, C. (2007). Modeling biocomplexity - actors, landscapes and alternative futures. Environmental Modelling \& Software, 22(5), 570-579.

https://doi.org/10.1016/j.envsoft.2005.12.033

Brockerhoff, E. G., Barbaro, L., Castagneyrol, B., Forrester, D. I., Gardiner, B., González-Olabarria, J. R., Lyver, P. O., Meurisse, N., Oxbrough, A., Taki, H., Thompson, I. D., van der Plas, F., \& Jactel, H. (2017). Forest biodiversity, ecosystem functioning and the provision of ecosystem services. Biodiversity and Conservation, 26(13), 3005-3035. https://doi.org/10.1007/s10531-017-1453-2

Burnham, K. P., \& Anderson, D. R. (2002a). Advanced Issues and Deeper Insights. In Model selection and multimodel inference: A practical information-theoretic approach (2nd ed, pp. 267-351). Springer.

Burnham, K. P., \& Anderson, D. R. (2002b). Information and Likelihood Theory: A Basis for Model Selection and Inference. In Model selection and multimodel inference: A practical information-theoretic approach (2nd ed, pp. 49-97). Springer.

Burnham, K. P., \& Anderson, D. R. (2004). Multimodel Inference: Understanding AIC and BIC in Model Selection. Sociological Methods \& Research, 33(2), 261-304.

https://doi.org/10.1177/0049124104268644

Burnham, K. P., Anderson, D. R., \& Huyvaert, K. P. (2011). AIC model selection and multimodel inference in behavioral ecology: Some background, observations, and comparisons. Behavioral Ecology and Sociobiology, 65(1), 23-35. https://doi.org/10.1007/s00265-010-1029-6

Carter, N. H., Shrestha, B. K., Karki, J. B., Pradhan, N. M. B., \& Liu, J. (2012). Coexistence between wildlife and humans at fine spatial scales. Proceedings of the National Academy of Sciences, 109(38), $15360-$ 15365. https://doi.org/10.1073/pnas.1210490109

Cassell, B. A., Scheller, R. M., Lucash, M. S., Hurteau, M. D., \& Loudermilk, E. L. (2019). Widespread severe wildfires under climate change lead to increased forest homogeneity in dry mixed-conifer forests.

Ecosphere, 10(11). https://doi.org/10.1002/ecs2.2934

Chow, C. C., \& Sarin, R. K. (2002). Known, Unknown, and Unknowable Uncertainties. Theory and Decision, $52,127-138$.

Devore, J. L. (2012). Simple Linear Regression and Correlation. In Probability \& Statistics for Engineering and the Sciences (8th ed., pp. 468-522). Brooks/Cole. 
Durham, W. A. (1991). Coevolution: Genes, culture, and human diversity. Stanford University Press.

Duveneck, M. J., Scheller, R. M., \& White, M. A. (2014). Effects of alternative forest management on biomass and species diversity in the face of climate change in the northern Great Lakes region (USA). Canadian Journal of Forest Research, 44(7), 700-710. https://doi.org/10.1139/cjfr-2013-0391

Elsawah, S., Filatova, T., Jakeman, A. J., Kettner, A. J., Zellner, M. L., Athanasiadis, I. N., Hamilton, S. H., Axtell, R. L., Brown, D. G., Gilligan, J. M., Janssen, M. A., Robinson, D. T., Rozenberg, J., Ullah, I. I. T., \& Lade, S. J. (2020). Eight grand challenges in socio-environmental systems modeling. Socio-Environmental Systems Modelling, 2, 16226. https://doi.org/10.18174/sesmo.2020a16226

European Commission (Ed.). (2003). Sustainable forestry and the European Union: Initiatives of the European Commission. Office for Official Publications of the European Communities.

Fischer, A. P. (2019). Adapting and coping with climate change in temperate forests. Global Environmental Change, 54, 160-171. https://doi.org/10.1016/j.gloenvcha.2018.10.011

Gan, J., Jarrett, A., \& Gaither, C. J. (2015). Landowner response to wildfire risk: Adaptation, mitigation or doing nothing. Journal of Environmental Management, 159, 186-191.

https://doi.org/10.1016/j.jenvman.2015.06.014

Gigerenzer, G., \& Selten, R. (Eds.). (2001). Bounded rationality: The adaptive toolbox. MIT Press.

Gilmour, D. A. (2016). Forty years of community-based forestry: A review of its extent and effectiveness. Food and agriculture organization of the United Nations.

Goertzel, B., Lian, R., Arel, I., de Garis, H., \& Chen, S. (2010). A world survey of artificial brain projects, Part II: Biologically inspired cognitive architectures. Neurocomputing, 74(1-3), 30-49.

https://doi.org/10.1016/j.neucom.2010.08.012

Gomory, R. E. (1995). The Known, the Unknown and the Unknowable. Scientific American, 272(6), 120120. https://doi.org/10.1038/scientificamerican0695-120

Grimm, V., Berger, U., Bastiansen, F., Eliassen, S., Ginot, V., Giske, J., Goss-Custard, J., Grand, T., Heinz, S. K., Huse, G., Huth, A., Jepsen, J. U., Jørgensen, C., Mooij, W. M., Müller, B., Pe'er, G., Piou, C., Railsback, S. F., Robbins, A. M., ... DeAngelis, D. L. (2006). A standard protocol for describing individual-based and agentbased models. Ecological Modelling, 198(1-2), 115-126.

https://doi.org/10.1016/j.ecolmodel.2006.04.023

Grimm, V., Berger, U., DeAngelis, D. L., Polhill, J. G., Giske, J., \& Railsback, S. F. (2010). The ODD protocol: A review and first update. Ecological Modelling, 221(23), 2760-2768.

https://doi.org/10.1016/j.ecolmodel.2010.08.019 
Grimm, V., Railsback, S. F., Vincenot, C. E., Berger, U., Gallagher, C., DeAngelis, D. L., Edmonds, B., Ge, J., Giske, J., Groeneveld, J., Johnston, A. S. A., Milles, A., Nabe-Nielsen, J., Polhill, J. G., Radchuk, V., Rohwäder, M.-S., Stillman, R. A., Thiele, J. C., \& Ayllón, D. (2020). The ODD Protocol for Describing AgentBased and Other Simulation Models: A Second Update to Improve Clarity, Replication, and Structural Realism. Journal of Artificial Societies and Social Simulation, 23(2), 7.

https://doi.org/10.18564/jasss.4259

Gustafson, E. J., Shifley, S. R., Mladenoff, D. J., Nimerfro, K. K., \& He, H. S. (2000). Spatial simulation of forest succession and timber harvesting using LANDIS. Canadian Journal of Forest Research, 30(1), 3243.

Halsey, L. G. (2019). The reign of the p-value is over: What alternative analyses could we employ to fill the power vacuum? Biology Letters, 15(5), 20190174. https://doi.org/10.1098/rsbl.2019.0174

Handler, S., Duveneck, M. J., Iverson, L., Peters, E., Scheller, R. M., Wythers, K. R., Brandt, L., Butler, P., Janowiak, M., Shannon, P. D., Swanston, C., Eagle, A. C., Cohen, J. G., Corner, R., Reich, P. B., Baker, T., Chhin, S., Clark, E., Fehringer, D., ... Ziel, Robert. (2014). Michigan forest ecosystem vulnerability assessment and synthesis: A report from the Northwoods Climate Change Response Framework project (NRS-GTR-129; p. NRS-GTR-129). U.S. Department of Agriculture, Forest Service, Northern Research Station. https://doi.org/10.2737/NRS-GTR-129

Hansen, L. P., \& Sargent, T. J. (2015). Uncertainty within economic models (1 Edition). World Scientific. Izenman, A. J. (2008). Modern Multivariate Statistical Techniques. Springer New York. https://doi.org/10.1007/978-0-387-78189-1

Janzen, D. H. (1980). When is it Coevolution? Evolution, 34(3), 611. https://doi.org/10.2307/2408229 Jurado, K., Ludvigson, S. C., \& Ng, S. (2015). Measuring Uncertainty. American Economic Review, 105(3), 1177-1216. https://doi.org/10.1257/aer.20131193

Keeley, J. E., Aplet, G. H., Christensen, N. L., Conard, S. G., Johnson, E. A., Omi, P. N., Peterson, D. L., \& Swetnam, T. W. (2009). Ecological foundations for fire management in North American forest and shrubland ecosystems (PNW-GTR-779; p. PNW-GTR-779). U.S. Department of Agriculture, Forest Service, Pacific Northwest Research Station. https://doi.org/10.2737/PNW-GTR-779

Kotseruba, I., \& Tsotsos, J. K. (2018). 40 years of cognitive architectures: Core cognitive abilities and practical applications. Artificial Intelligence Review. https://doi.org/10.1007/s10462-018-9646-y

Krofcheck, D. . J., Remy, C. C., Keyser, A. R., \& Hurteau, M. D. (2019). Optimizing Forest Management Stabilizes Carbon Under Projected Climate and Wildfires. Journal of Geophysical Research: Biogeosciences, 124(10), 3075-3087. https://doi.org/10.1029/2019JG005206 
Kwakkel, J. H., Walker, W. E., \& Marchau, V. A. W. J. (2010). Classifying and communicating uncertainties in model-based policy analysis. International Journal of Technology, Policy and Management, 10(4), 299. https://doi.org/10.1504/IJTPM.2010.036918

Langley, P. (2017). Progress and Challenges in Research on Cognitive Architectures. Proceedings of the Thirty-First AAAl Conference on Artificial Intelligence (AAAl-17), 7.

Langley, P., Laird, J. E., \& Rogers, S. (2009). Cognitive architectures: Research issues and challenges. Cognitive Systems Research, 10(2), 141-160. https://doi.org/10.1016/j.cogsys.2006.07.004

Lempert, R. J. (2019). Robust Decision Making (RDM). In V. A. W. J. Marchau, W. E. Walker, P. J. T. M. Bloemen, \& S. W. Popper (Eds.), Decision Making under Deep Uncertainty: From Theory to Practice (pp. 23-51). Springer International Publishing. https://doi.org/10.1007/978-3-030-05252-2

Lempert, R. J., Groves, D. G., Popper, S. W., \& Bankes, S. C. (2006). A General, Analytic Method for Generating Robust Strategies and Narrative Scenarios. Management Science, 52(4), 514-528. https://doi.org/10.1287/mnsc.1050.0472

Lempert, R. J., Popper, S. W., \& Banks, S. C. (2003). The Challenge of Long-Term Policy Analysis. In Shaping the Next One Hundred Years: New Methods for Quantitative, Long-Term Policy Analysis (1st ed., pp. 1-9). RAND Corporation. http://www.jstor.com/stable/10.7249/mr1626rpc.14

Lempert, R. J., Schlesinger, M. E., \& Bankes, S. C. (1996). When we don't know the costs or the benefits: Adaptive strategies for abating climate change. Climatic Change, 33(2), 235-274. https://doi.org/10.1007/BF00140248

Lucash, M. S., Ruckert, K. L., Nicholas, R. E., Scheller, R. M., \& Smithwick, E. A. H. (2019). Complex interactions among successional trajectories and climate govern spatial resilience after severe windstorms in central Wisconsin, USA. Landscape Ecology, 34(12), 2897-2915. https://doi.org/10.1007/s10980-019-00929-1

Lucash, M. S., Scheller, R. M., J. Gustafson, E., \& R. Sturtevant, B. (2017). Spatial resilience of forested landscapes under climate change and management. Landscape Ecology, 32(5), 953-969. https://doi.org/10.1007/s10980-017-0501-3

Maier, H. R., Guillaume, J. H. A., van Delden, H., Riddell, G. A., Haasnoot, M., \& Kwakkel, J. H. (2016). An uncertain future, deep uncertainty, scenarios, robustness and adaptation: How do they fit together? Environmental Modelling \& Software, 81, 154-164. https://doi.org/10.1016/j.envsoft.2016.03.014

Marchau, V. A. W. J., Walker, W. E., Bloemen, P. J. T. M., \& Popper, S. W. (Eds.). (2019). Decision Making under Deep Uncertainty: From Theory to Practice. Springer International Publishing. https://doi.org/10.1007/978-3-030-05252-2 
Maxwell, C. J., Serra-Diaz, J. M., Scheller, R. M., \& Thompson, J. R. (2020). Co-designed management scenarios shape the responses of seasonally dry forests to changing climate and fire regimes. Journal of Applied Ecology, 57(7), 1328-1340. https://doi.org/10.1111/1365-2664.13630

Mayer, A. L., \& Rouleau, M. D. (2013). ForestSim Model of Impacts of Smallholder Dynamics: Forested Landscapes of the Upper Peninsula of Michigan. International Journal of Forestry Research, 2013, 1-13. https://doi.org/10.1155/2013/520207

MEA (Ed.). (2003). Ecosystems and human well-being: A framework for assessment. Island Press.

Messier, C., Puettmann, K., Filotas, E., \& Coates, D. (2016). Dealing with Non-linearity and Uncertainty in Forest Management. Current Forestry Reports, 2(2), 150-161. https://doi.org/10.1007/s40725-016-0036$x$

Meyfroidt, P. (2013). Environmental cognitions, land change, and social-ecological feedbacks: An overview. Journal of Land Use Science, 8(3), 341-367. https://doi.org/10.1080/1747423X.2012.667452

Mladenoff, D. J., \& He, H. S. (1999). Design, behavior and application of LANDIS, an object-oriented model of forest landscape disturbance and succession. In Spatial modeling of forest landscape change: Approaches and applications (pp. 125-162). Cambridge University Press.

Müller, B., Bohn, F., Dreßler, G., Groeneveld, J., Klassert, C., Martin, R., Schlüter, M., Schulze, J., Weise, H., \& Schwarz, N. (2013). Describing human decisions in agent-based models - ODD + D, an extension of the ODD protocol. Environmental Modelling \& Software, 48, 37-48.

https://doi.org/10.1016/j.envsoft.2013.06.003

Nuismer, S. L. (2017). Introduction to Coevolutionary Theory. W. H. Freeman and Company.

Ostrom, E. (1999). Self-Governance and Forest Resources (p. 19) [Occasional Paper No. 20]. Center for International Forestry Research.

Park, A., Puettmann, K., Wilson, E., Messier, C., Kames, S., \& Dhar, A. (2014). Can Boreal and Temperate Forest Management be Adapted to the Uncertainties of 21 st Century Climate Change? Critical Reviews in Plant Sciences, 33(4), 251-285. https://doi.org/10.1080/07352689.2014.858956

Puettmann, K. J., Coates, K. D., \& Messier, C. (2009). A Critique of Silviculture: Managing for Complexity. Island Press.

R Core Team. (2020). R: A language and environment for statistical computing (3.6.3) [R]. R Foundation for Statistical Computing. http://www.R-project.org/

Rammer, W., \& Seidl, R. (2015). Coupling human and natural systems: Simulating adaptive management agents in dynamically changing forest landscapes. Global Environmental Change, 35, 475-485. https://doi.org/10.1016/j.gloenvcha.2015.10.003 
Rinaldi, F., \& Jonsson, R. (2020). Accounting for uncertainty in forest management models. Forest Ecology and Management, 468, 118186. https://doi.org/10.1016/j.foreco.2020.118186

Robertson, G., Gaulke, P., McWilliams, R., LaPlante, S., \& Guldin, R. (2011). National Report on Sustainable Forests-2010 (FS-979; p. 212). USDA Forest Service.

Rosenzweig, C., Casassa, G., Karoly, D. J., Imeson, A., Rawlins, S., Root, T. L., Seguin, B., \& Tryjanowski, P. (2007). Assessment of observed changes and responses in natural and managed systems. In M. L. Parry, O. F. Canziani, J. P. Palutikof, P. J. van der Linden, \& C. E. Hanson (Eds.), Climate Change 2007: Impacts, Adaptation and Vulnerability. Contribution of Working Group II to the Fourth Assessment Report of the Intergovernmental Panel on Climate Change (pp. 79-131). Cambridge University Press.

Rouleau, M., \& Zupko, R. (2019). Agent-Based Modeling for bioenergy sustainability assessment. Landscape and Urban Planning, 188, 54-63. https://doi.org/10.1016/j.landurbplan.2019.04.019

Scheller, R. M., Domingo, J. B., Sturtevant, B. R., Williams, J. S., Rudy, A., Gustafson, E. J., \& Mladenoff, D. J. (2007). Design, development, and application of LANDIS-II, a spatial landscape simulation model with flexible temporal and spatial resolution. Ecological Modelling, 201(3-4), 409-419.

https://doi.org/10.1016/j.ecolmodel.2006.10.009

Scheller, R. M., Kretchun, A. M., Loudermilk, E. L., Hurteau, M. D., Weisberg, P. J., \& Skinner, C. (2018). Interactions Among Fuel Management, Species Composition, Bark Beetles, and Climate Change and the Potential Effects on Forests of the Lake Tahoe Basin. Ecosystems, 21(4), 643-656.

https://doi.org/10.1007/s10021-017-0175-3

Scheller, R. M., \& Mladenoff, D. J. (2004). A forest growth and biomass module for a landscape simulation model, LANDIS: Design, validation, and application. Ecological Modelling, 180(1), 211-229. https://doi.org/10.1016/j.ecolmodel.2004.01.022

Schwarz, G. (1978). Estimating the Dimension of a Model. The Annals of Statistics, 6(2), 461-464. https://doi.org/10.1214/aos/1176344136

Seidl, R., \& Lexer, M. J. (2013). Forest management under climatic and social uncertainty: Trade-offs between reducing climate change impacts and fostering adaptive capacity. Journal of Environmental Management, 114, 461-469. https://doi.org/10.1016/j.jenvman.2012.09.028

Selten, R. (1998). Features of experimentally observed bounded rationality. European Economic Review, 42(3-5), 413-436. https://doi.org/10.1016/S0014-2921(97)00148-7

Shaw, B. D. (2017a). Uncertainty analysis of experimental data with R. CRC Press/Taylor \& Francis Group.

Shaw, B. D. (2017b). Uncertainty of a Measured Quantity. In Uncertainty analysis of experimental data with $R$ (pp. 75-90). CRC Press/Taylor \& Francis Group. 
Shepherd, B., \& Whittington, J. (2006). Response of Wolves to Corridor Restoration and Human Use Management. Ecology and Society, 11(2), art1. https://doi.org/10.5751/ES-01813-110201

Simon, H. A. (1957). Models of man, social and rational: Mathematical essays on rational human behavior in a social setting. Wiley.

Simon, H. A. (1960). The new science of management decision. Harper.

Sotnik, G. (2018). The SOSIEL Platform: Knowledge-based, cognitive, and multi-agent. Biologically Inspired Cognitive Architectures, 26, 103-117. https://doi.org/10.1016/j.bica.2018.09.001

Sotnik, G. (2020). The Doubly-Bounded Rationality of an Artificial Agent and its Ability to Represent the Bounded Rationality of a Human Decision-Maker in Policy-Relevant Situations. Journal of Experimental \& Theoretical Artificial Intelligence, 32(5), 727-749. https://doi.org/10.1080/0952813X.2019.1672797

Swanston, C., Brandt, L. A., Janowiak, M. K., Handler, S. D., Butler-Leopold, P., Iverson, L., Thompson III, F. R., Ontl, T. A., \& Shannon, P. D. (2018). Vulnerability of forests of the Midwest and Northeast United States to climate change. Climatic Change, 146(1-2), 103-116. https://doi.org/10.1007/s10584-017-2065-2

Todd, P. M., Gigerenzer, G., \& ABC Research Group. (2012). Ecological rationality: Intelligence in the world. Oxford University Press.

Turner, M. G., \& Romme, W. H. (1994). Landscape dynamics in crown fire ecosystems. Landscape Ecology, 9(1), 59-77. https://doi.org/10.1007/BF00135079

Uusitalo, L., Lehikoinen, A., Helle, I., \& Myrberg, K. (2015). An overview of methods to evaluate uncertainty of deterministic models in decision support. Environmental Modelling \& Software, 63, 24-31. https://doi.org/10.1016/j.envsoft.2014.09.017

Walker, W. E., Harremoës, P., Rotmans, J., van der Sluijs, J. P., van Asselt, M. B. A., Janssen, P., \& Krayer von Krauss, M. P. (2003). Defining Uncertainty: A Conceptual Basis for Uncertainty Management in ModelBased Decision Support. Integrated Assessment, 4(1), 5-17. https://doi.org/10.1076/iaij.4.1.5.16466

Walker, W. E., Lempert, R. J., \& Kwakkel, J. H. (2013). Deep Uncertainty. In Encyclopedia of Operations Research and Management Science. Springer. https://doi.org/10.1007/978-1-4419-1153-7_1140

Walker, W. E., Rahman, S. A., \& Cave, J. (2001). Adaptive policies, policy analysis, and policy-making. European Journal of Operational Research, 128(2), 282-289. https://doi.org/10.1016/S03772217(00)00071-0

Wear, D. N., Huggett, R., Li, R., Perryman, B., \& Liu, S. (2013). Forecasts of Forest Conditions in U.S. Regions Under Future Scenarios A Technical Document Supporting the Forest Service 2010 RPA Assessment. USDA. 
Weaver, C. P., Lempert, R. J., Brown, C., Hall, J. A., Revell, D., \& Sarewitz, D. (2013). Improving the contribution of climate model information to decision making: The value and demands of robust decision frameworks: The value and demands of robust decision frameworks. Wiley Interdisciplinary Reviews: Climate Change, 4(1), 39-60. https://doi.org/10.1002/wcc.202

Winter, G. J., \& Fried, J. S. (2000). Homeowner Perspectives on Fire Hazard, Responsibility, and Management Strategies at the Wildland-Urban Interface. Society \& Natural Resources, 13(1), 33-49. https://doi.org/10.1080/089419200279225

Yousefpour, R., Jacobsen, J. B., Thorsen, B. J., Meilby, H., Hanewinkel, M., \& Oehler, K. (2012). A review of decision-making approaches to handle uncertainty and risk in adaptive forest management under climate change. Annals of Forest Science, 69(1), 1-15. https://doi.org/10.1007/s13595-011-0153-4

Zupko, R., \& Rouleau, M. (2019). ForestSim: Spatially explicit agent-based modeling of non-industrial forest owner policies. SoftwareX, 9, 117-125. https://doi.org/10.1016/j.softx.2019.01.008

\section{Figures}

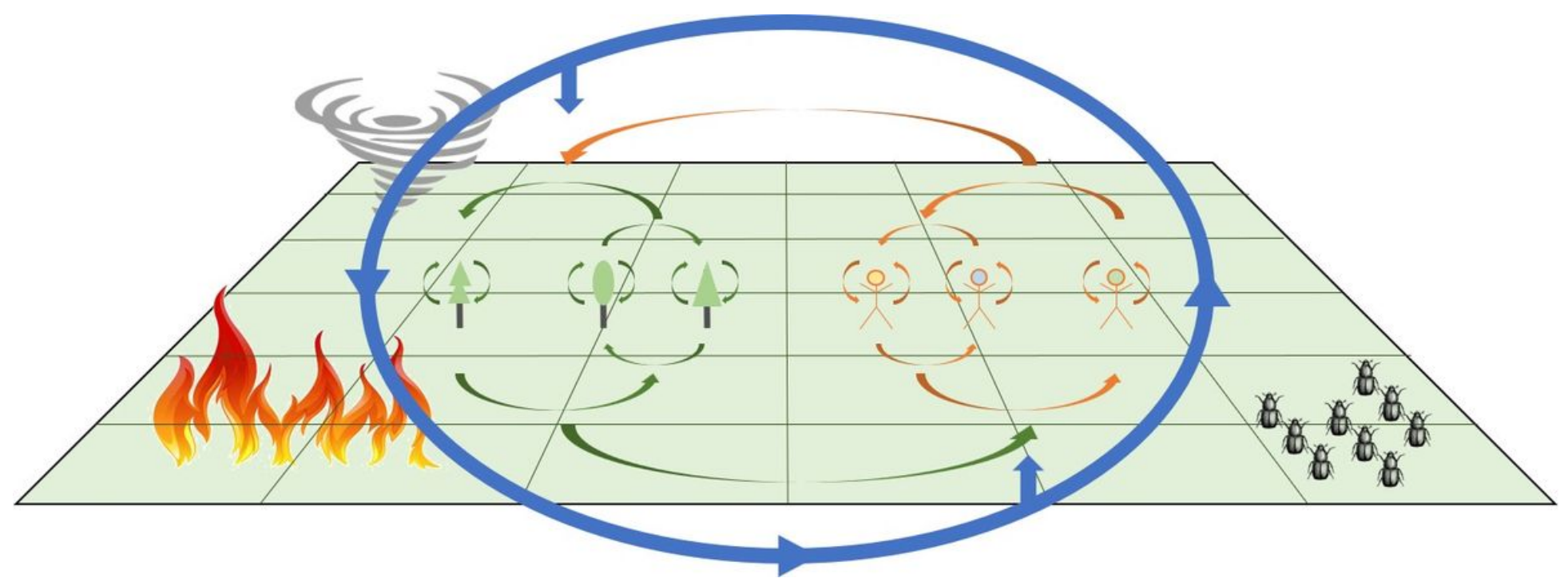

Figure 1

A process-focused depiction of LANDIS-II with SHE. The (orange) arrows between the human figures represent individual and social processes, the (green) arrows between the trees represent processes within and among tree cohorts, the (orange and green) arrows between the human figures and tree cohorts represent bidirectional influence and feedback, and the (blue) oval and arrows around both represent climate. These processes occur on a two-dimensional landscape, which may also include disturbances, such as fire, insect infestations, and windthrow events. 


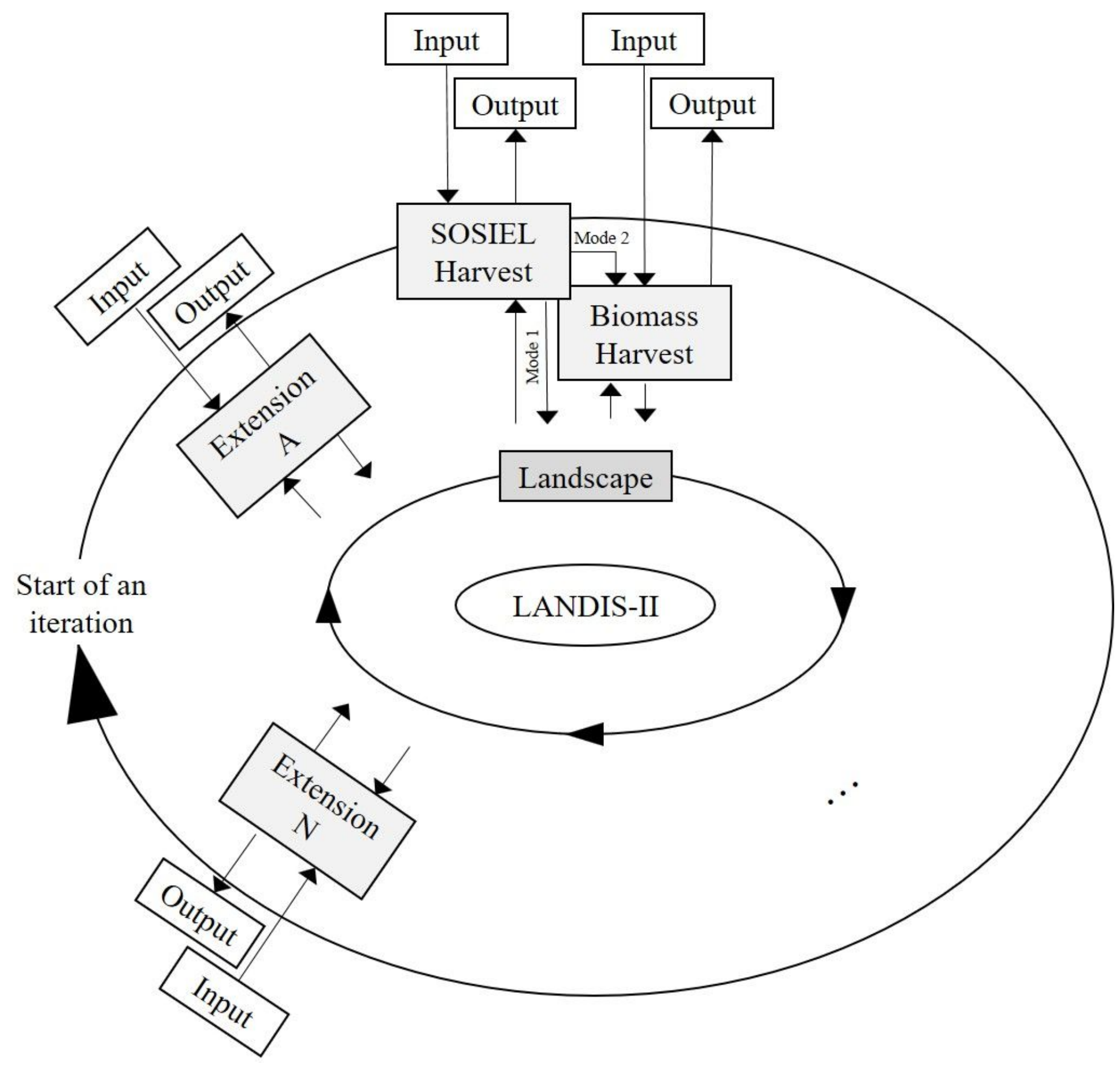

Figure 2

SHE in the context of LANDIS-II, BHE, and additional LANDIS-II extensions. At each timestep, LANDIS-II calls on different extensions to act on the landscape. In this study, two other extensions are included, Biomass Succession and Base Wind, both of which are called on before SHE. In Mode 1, SHE, in turn, calls on the SOSIEL algorithm to analyze landscape conditions and choose decision options and then uses LANDIS-II's harvest management library to implement them. In Mode 2, SHE calls on the SOSIEL algorithm to analyze landscape conditions and choose decision options and on BHE to implement them. 


\section{SOSIEL \\ Harvest}

\section{SOSIEL \\ Biomass algorithm \\ Harvest}

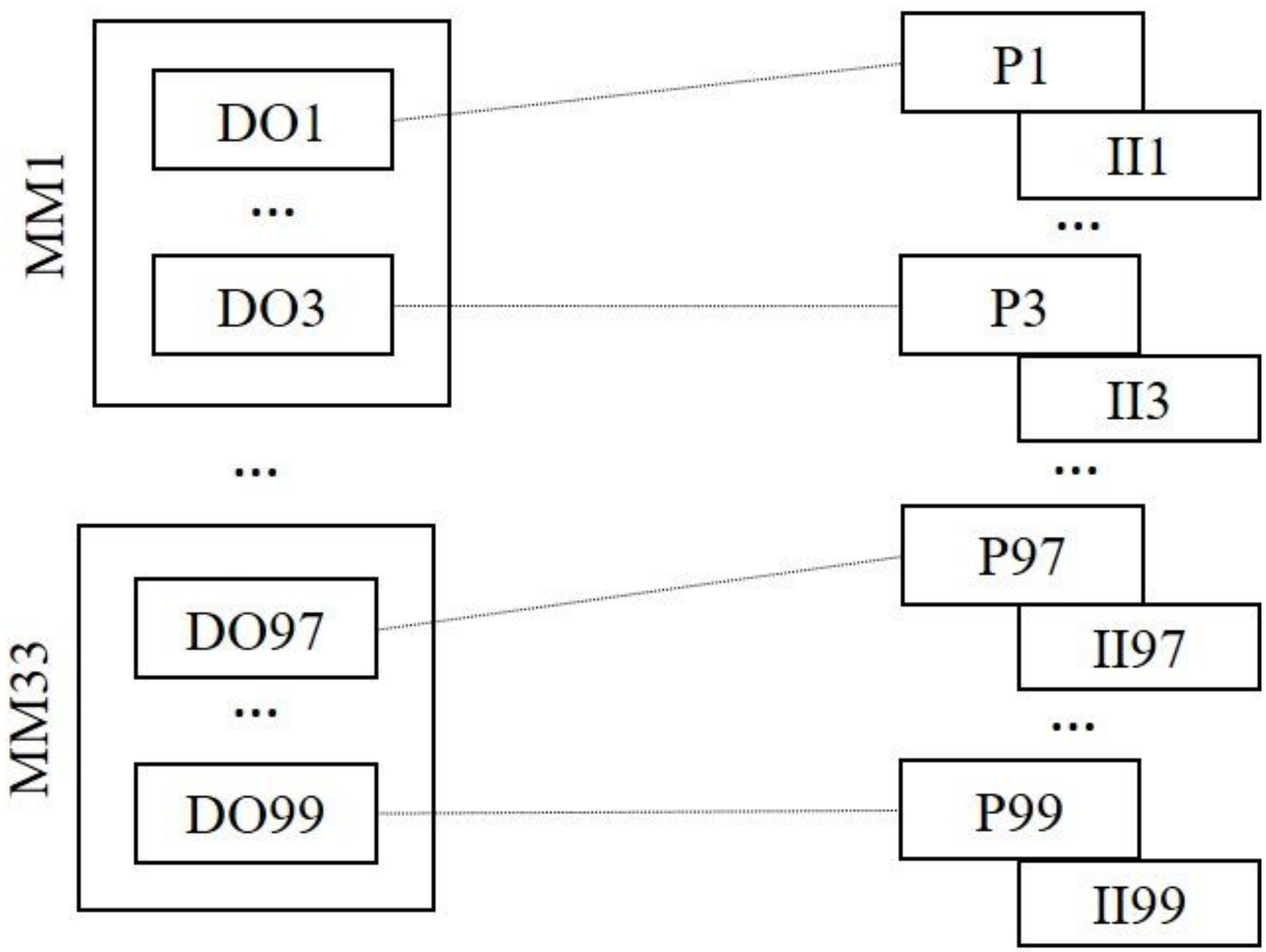

Figure 3

SHE's pairing of the SOSIEL algorithm's decision options (DOs) with BHE's prescriptions (Ps; e.g., clear cut or selectively cut certain amounts of select species) and implementation instructions (IIs). The SOSIEL algorithm organizes the decision options that are variants (substitutes) of one another into mental models. 


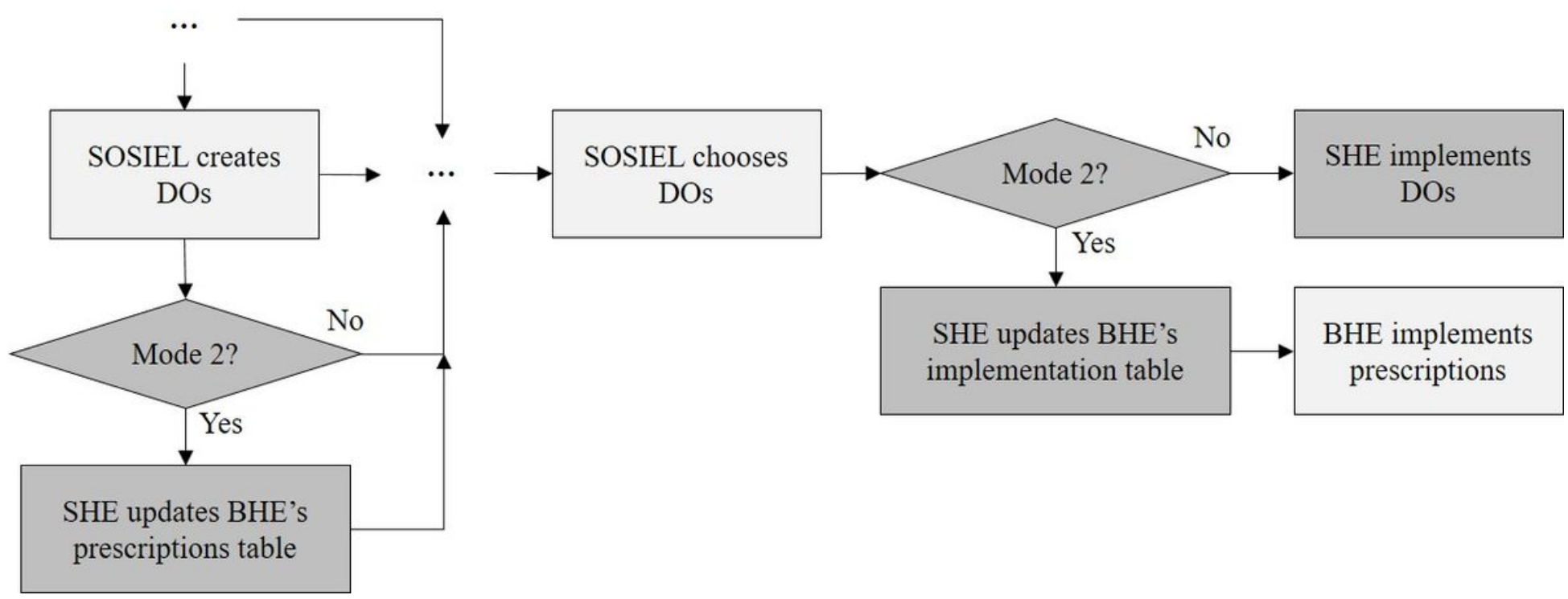

\section{Figure 4}

SHE's process flow for creating and implementing decision options (DOs) and prescriptions. SHE's decision points and processes are in dark grey, and select SOSIEL algorithm and BHE processes are in light grey. The three dots represent other SOSIEL processes that are not directly related to the process of creating new decision options. 

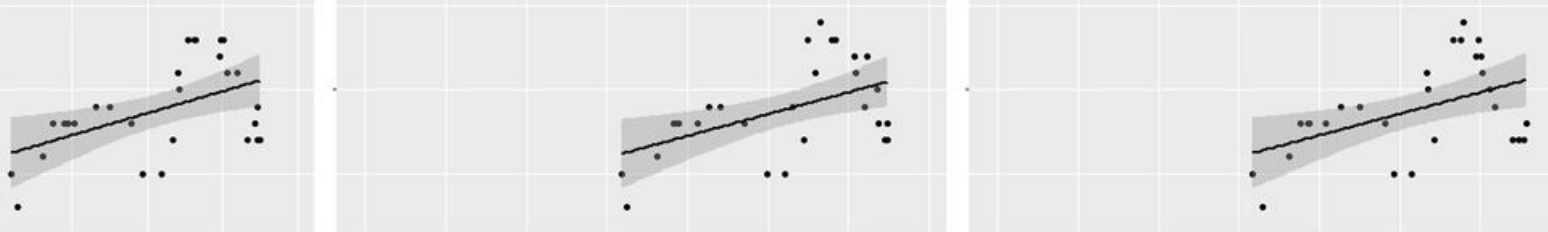

$80-$

A2 R1: $r^{2}=0.46$

A2 R2: $r^{2}=0.4$

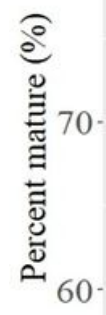

80 .

$\vdots \quad$ A3 R1 : $r^{2}=0.82$

70.

60

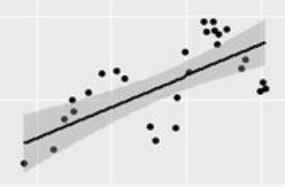

70

:

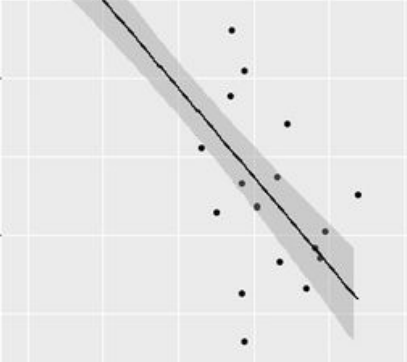

0.0

$5.0 \quad 7.5$

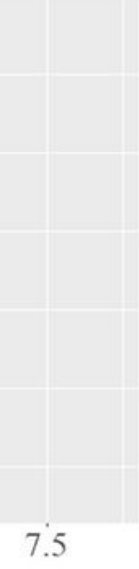

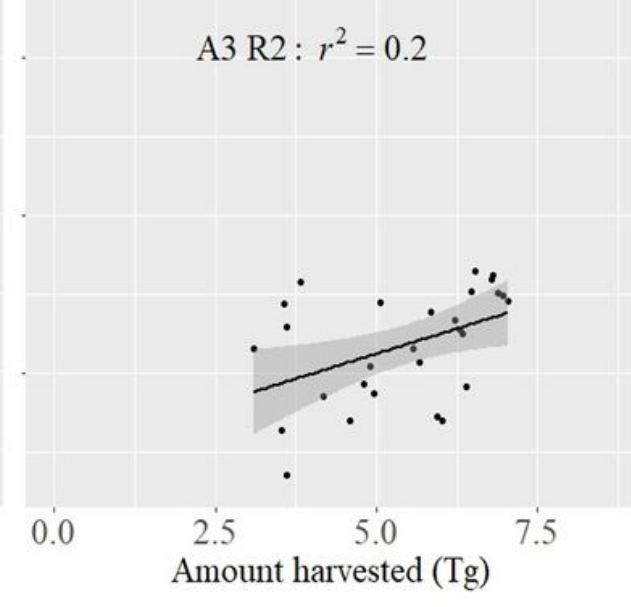

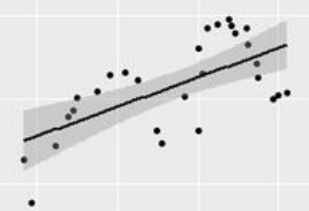

A2 R3: $r^{2}=0.46$

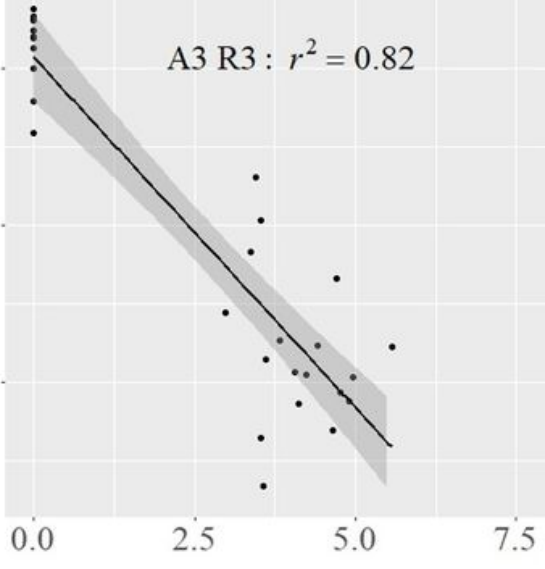

\section{Figure 5}

A comparison of the three simulation replicates (R1-R3) of the three modeling approaches (A1-A3). Dots indicate the percent of mature trees (\%) and biomass harvested $(\mathrm{Tg})$ at corresponding years, solid line indicates the best-fit regression, and the gray area indicates the $95 \%$ confidence interval.

\section{Supplementary Files}

This is a list of supplementary files associated with this preprint. Click to download. 
- SHEMode2ODDprotocol.docx

Page $30 / 30$ 